\title{
ANÁLISE DO DESMATAMENTO NAS ÁREAS DE INFLUÊNCIA DA BR-421 E AS PRESSÕES SOBRE ÁREAS ESPECIAIS NO OESTE DE RONDÔNIA
}

\author{
Jessica Maiara Alves Lopes ${ }^{1}$ \\ Alex Mota dos Santos ${ }^{2}$ \\ Fabrizia Gioppo Nunes ${ }^{3}$
}

\section{Resumo}

O objetivo da pesquisa é analisar as principais alterações antrópicas nas áreas de influência da rodovia BR-421 e as pressões sobre o meio físico, em parte das áreas especiais do tipo terras indígenas, localizadas no oeste de Rondônia. Foram utilizados métodos indiretos de análise, nomeadamente o processamento digital de imagens e o cálculo de um índice de pressão antrópica. Além do uso dos métodos indiretos empregou-se um questionário para avaliar a percepção de estudantes indígenas que residem numa das terras encontradas nas áreas de influências da rodovia federal BR-421. Os resultados revelaram que o desmatamento se consolidou nos anos 2000 através da implantação da rodovia BR-421 e a conversão da paisagem revelou-se pela agropecuária, que cresceu $547,82 \%$ no período da análise. Das três áreas sob influência da rodovia BR-421, a Área de Influência Direta (AID) foi a que apresentou maior taxa de crescimento de conversão da floresta em áreas agropecuárias, 543,58\%.

Palavras-chave: Povos Indígenas, Rodovias, Geoprocessamento, Amazônia.

\section{ANALYSIS OF DISMANTLING IN BR-421 AREAS OF INFLUENCE AND PRESSURES ON SPECIAL AREAS IN WEST OF RONDÔNIA/STATE}

\begin{abstract}
Objective of the research is to analyze the main anthropogenic changes in the areas of influence of the BR-421 highway and the pressures on the physical environment in part of the special areas of the indigenous land type located in the west of Rondonia. Indirect methods of landscape analysis were used, namely the digital image processing and the calculation of an anthropic pressure index. In addition to the use of indirect methods, a questionnaire was used to evaluate the perception of indigenous students residing in one of the lands found in the areas of influence of federal highway BR-421. Results had showed that deforestation was consolidated in the year
\end{abstract}

\footnotetext{
1 Bacharel em Engenharia Ambiental pela Fundação Universidade Federal de Rondônia - UNIR. Email: jessicamayara_26@hotmail.com.

${ }^{2}$ Professor adjunto da Universidade Federal de Goiás (UFG), da Faculdade de Ciência e Tecnologia-FCT (Brasil). Vinculado ao programa de pós-graduação em Tecnologia de Processos Sustentáveis, do Instituto Federal de Educação, Ciência e Tecnologia de Goiás (IFG-Goiás). Email: alex.geotecnologias@gmail.com.
}

${ }^{3}$ Professora adjunta da Universidade Federal de Goiás (UFG), no Instituto de Estudos Sócio Ambiental-IESA (Brasil). Vinculada ao programa de pós-graduação em Geografia (IESA/UFG). fabrizia.iesa.ufg@gmail.com. 
2000 through the implementation of federal highway BR-421 and the conversion of the landscape was revealed by the agricultural sector, which grew by $547.82 \%$ in the period of analysis. Finally, of the three areas under federal highway BR-421, the Direct Influence Area (DIA) was the one with the highest growth rate of forest conversion in agricultural areas, $543.58 \%$.

Keywords: indigenous peoples, highways, remote sensing, amazon-forest

\section{ANALYSIS OF DEFORESTATION IN BR-421 INFLUENCE AREAS AND PRESSURES ON SPECIAL AREAS IN WEST RONDONIA}

\section{Resumen}

El objetivo de esta investigación es analizar las principales alteraciones antropogénicas en las áreas de influencia de la carretera BR-421 y las presiones sobre el entorno físico, en parte de las áreas especiales de tipo de tierras indígenas, ubicadas en el oeste de Rondônia. Se utilizaron métodos de análisis indirectos, a saber, procesamiento de imágenes digitales y cálculo de un índice de presión antrópica. Además del uso de métodos indirectos, se utilizó un cuestionario para evaluar la percepción de los estudiantes indígenas que residen en una de las tierras que se encuentran en las áreas de influencia de la carretera federal BR-421. Los resultados revelaron que la deforestación se consolidó en 2000 a través de la implementación de la carretera BR-421 y la conversión del paisaje fue revelada por la agricultura, que creció $547.82 \%$ en el período bajo análisis. Las tres áreas bajo la influencia de la carretera BR-421, el Área de Influencia Directa (IDA), fue la que tuvo la tasa de crecimiento más alta de conversión forestal en áreas agrícolas, $543.58 \%$.

Palabras-clave: Pueblos Indígenas, Carreteras, Geoprocesamiento, Amazonas.

\section{INTRODUÇÃO}

Os Programas Nacionais de Incentivo ao Crescimento Econômico normalmente financiam projetos de infraestrutura, especialmente a viária. Isso porquê os transportes, com seus sistemas de redes e fluxos "desempenham funções estratégicas no conjunto de serviços produtivos dos territórios" (CASTILHO, 2014, p. 18). Além disso, sabe-se que o sistema de rede macro viária, juntamente aos aspectos políticos e ideológicos, são os principais fatores que orientam os modelos de ocupação do espeço e, portanto, o tema é recorrente nas literaturas nacionais e internacionais (PONS e REYNÉS, 2004; RODRIGUE et al., 2006; CASTILHO, 2014).

No caso da Amazônia Legal os programas financiados pelo Governo Nacional concentram seus esforços sobre a abertura de estradas em diversos estados da região, tendo como interesse promover o desenvolvimento econômico local. Assim, segundo Kohlhepp 
Análise do desmatamento nas áreas de influência da BR-421 e as

(2002) a construção dessas estradas é baseada no conceito de planejamento de eixos de desenvolvimento, que influenciam diretamente, no processo de desmatamento. Nesse sentido, Marcuartú et al. (2017, p. 36) afirmam que,

[...] ao se discutir as diversas problemáticas que envolvem o Bioma Amazônico, pode-se considerar como uma das questões mais urgentes, a perda inexorável de funções essenciais fornecidas pelas florestas, como consequência do avanço do desmatamento.

Desta forma, Santos et al. (2018) destacam a ação do Programa Integrado de Desenvolvimento do Noroeste do Brasil (POLONOROESTE), executado durante os anos de 1980. O programa foi criado pelo Decreto Federal n ${ }^{\circ} 86.029$ de 27 de maio de 1981, com recursos provenientes do Governo brasileiro e do Banco Mundial, responsáveis por todo o processo de ocupação não indígena, vivenciado no estado de Rondônia.

De acordo com Santos et al. (2018), as influências mais marcantes desse período foram sem dúvidas, os projetos de colonização do Instituto Nacional de Reforma Agrária (INCRA), e a pavimentação da BR-364. Neste contexto, diversos são os autores que concordam que foi nesse período que ocorreu a consolidação da ocupação e povoamento de Rondônia (FEARNSIDE, 1989; AMARAL, 1998; CIM, 2003; OLIVEIRA, 2003). Nesse sentido, as atividades do INCRA podem ser agrupadas em Projetos Integrados de Colonização (PICs), Projetos de Assentamentos Dirigidos (PADs) e Projetos de Assentamentos (PAs). Além desses, destacam-se também os projetos de colonização privados, dos quais a Colonizadora Itaporanga e a Colonizadora Calama, foram as mais marcantes (OLIVEIRA, 2003). Contudo, para que obtivessem êxitos nesses projetos o acesso aos loteamentos deveria ser facilitado. Portanto, o meio de articulação que o governo utilizava para facilitar tal acesso era a abertura de novas estradas (RIO TERRA, 2011).

Como efeito, destaca-se o fato de que a maioria das estradas construídas durante o POLONOROESTE, cruzou e/ou margeou Áreas Indígenas e Unidades de Conservação (FEANRSIDE e FERREIRA, 1984). Assim, Bastos (2009) ao concordar com Fearnside (2005) traz a luz ao debate a construção de estradas clandestinas nas proximidades de terras indígenas. Essas estradas geraram inúmeros conflitos entre colonos e comunidades tradicionais, levando diversos grupos étnicos ao extermínio (GREENBAUM, 1984).

Segundo Euler et al. (2008), devido a esse fato, o POLONOROESTE foi alvo de críticas de várias organizações não governamentais (ONGs), o que resultou no planejamento de um 
novo programa conhecido como Projeto Agropecuário e Florestal de Rondônia (PLANAFLORO). Este programa tinha por princípio amenizar os impactos causados durante o período de execução do POLONOROESTE. Entretanto, o programa se mostrou ineficiente, pois durante seu período de execução houveram a construção de estradas secundárias com apoio direto de madeireiros da região (PEDOSLIKIM et al., 1999). Assim, Feanrside (1989) afirma que as estradas secundárias foram criadas, após a pavimentação da BR-364, que estava intimamente ligada à taxa de chegada de novos imigrantes. A exemplo disso, têm-se a abertura das rodovias BR-429, BR-425 e BR-421, que são de extrema importância para pequenos e grandes produtores (BORGES, 2012).

Neste contexto, destaca-se o papel da BR-421, que começou a ser construída na década de 1980, com o objetivo de ligar o município de Ariquemes a Guajará-Mirim (ARCADIS TETRAPLAN, 2011). Esta rodovia foi construída a partir de incentivos financeiros promovidos por madeireiros. Isto fez com que a construção fosse implementada em uma área de proteção ambiental, visto que atravessa duas unidades de conservação sendo elas: o Parque Nacional dos Pacaás Novos e o Parque Estadual de Guajará-Mirim, além da proximidade a quatro Terras Indígenas: Karipuna Igarapé Ribeirão, Igarapé Lage e Uru Eu Wau Wau (FEARNSIDE e FERREIRA, 1984).

Para Borges (2012) a região onde se encontra localizada esta rodovia, era a área de maior nível de conservação ambiental do estado Rondônia, nos idos dos primeiros anos do século XXI. Ao mesmo tempo, se configura ainda nos dias de hoje, como uma das áreas mais conflituosas, devido a diversas nvasões em áreas protegidas. Porém, após 30 anos de abertura a estrada foi interditada pelo MPF/RO. Contudo, com a enchente do rio Madeira no ano de 2014 a BR-421, voltou a ser utilizada, sob o argumento de que era a única alternativa de conexão entre os municípios da região

A intenção de reativar a BR-421 era tão importante no cenário econômico local e regional, que a então ex-presidente da república, Dilma Rousseff, "defendeu a Estrada Parque", alegando sua fundamental importância para a ligação dos municípios isolados com a BR-364" (SANTOS, 2014, p.173). O nome Estrada Parque, atribuída a rodovia estadual 420, foi uma estratégia do poder, político e econômico local à época, para burlar a proibição imposta pela justiça federal às obras da rodovia federal BR-421. O fato é que a Estrada Parque ou rodovia estadual 420 tem o mesmo traçado da rodovia 421. Sua abertura impulsionou o fluxo de pessoas 
Análise do desmatamento nas áreas de influência da BR-421 e as

em busca de terras baratas e dos recursos naturais abundantes, propiciando assim, o aumento da pressão antrópica sobre as Terras Indígenas e Unidades de Conservação (SANTOS, 2014).

Diante do cenário estabelecido, trabalhos que visem estudar as pressões antrópicas derivadas das rodovias são de grande importância. Neste sentido, o objetivo desta pesquisa foi o de analisar, quantificar e avaliar as principais alterações antrópicas, derivadas de ações não indígenas, ao longo da BR-421 e as suas influências sobre as terras indígenas Karipuna, Uru Eu Wau, Igarapé Ribeirão e Igarapé Lage.

\section{ÁREA DE ESTUDO}

A pesquisa foi desenvolvida na porção oeste do estado de Rondônia, possuindo uma área de $33.266,11 \mathrm{~km}^{2}$, delimitada pela proximidade que as terras indígenas Karipuna, Igarapé Ribeirão, Igarapé Lage e Uru Eu Wau apresentaram com a rodovia federal BR-421 (Figura 1).

Figura 1- Mapa de localização de parte das terras indígenas que se encontram em torno da Rodovia Federal BR-421.

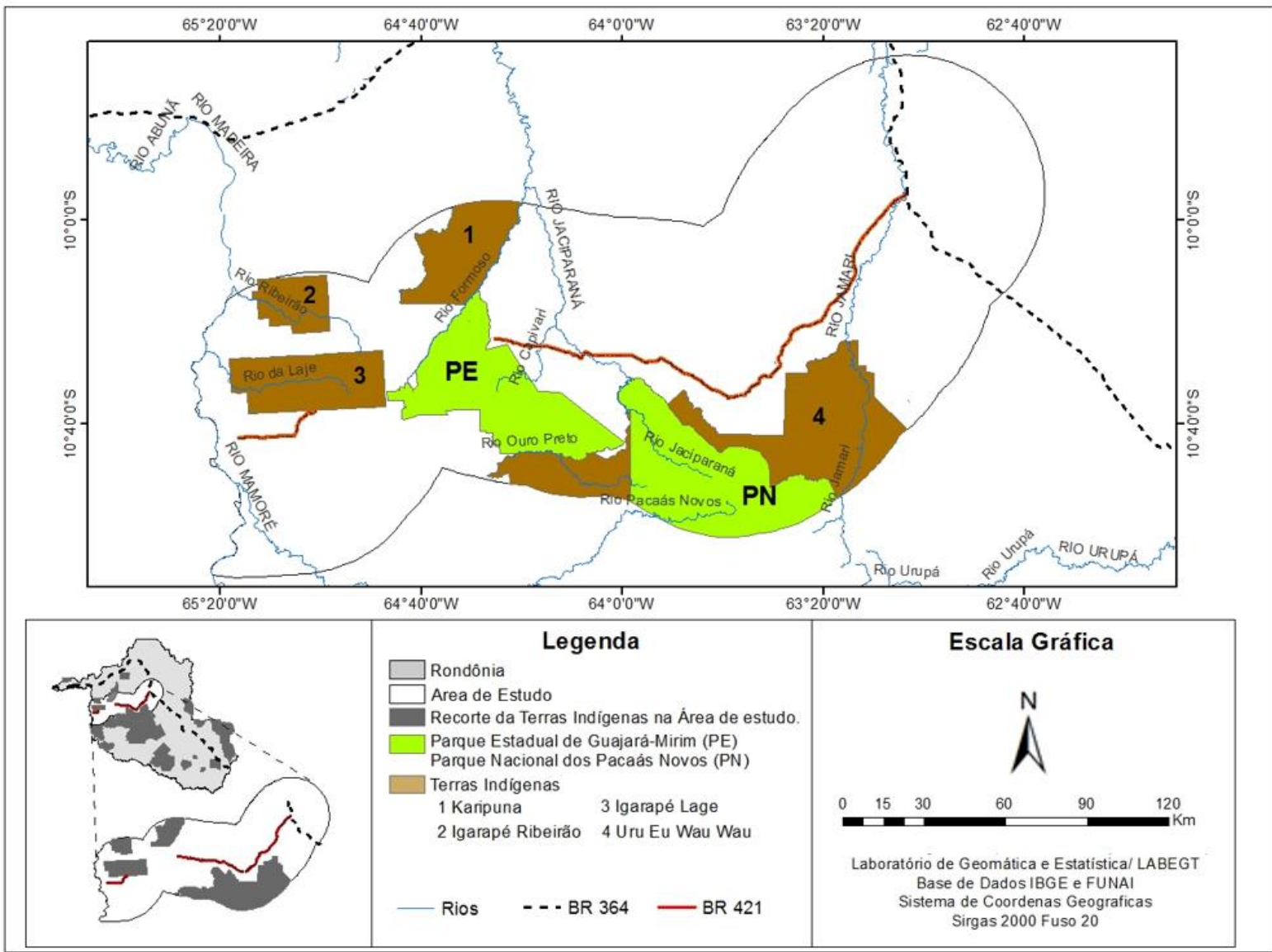

Fonte: elaborado pelos autores 
Desta, destaca-se que 39,66\% da superfície de estudo é ocupada por áreas especiais (terras indígenas, parques estadual e federal), sendo que 14,42\%, pela terra indígena Uru Eu Wau Wau, a maior em área no estado de Rondônia.

A terra indígena Karipuna está localizada no extremo norte da área de estudo, entre os municípios de Porto Velho e Nova-Mamoré. Segundo o último censo indígena do Instituto Brasileiro de Geografia e Estatística (IBGE), vivem aproximadamente 31 indivíduos da etnia Karipuna na terra indígena de mesmo nome (IBGE, 2015). De acordo com Leão et al. (2005), o tipo de vegetação encontrada nessa região é a Floresta Ombrófila Aberta, onde destacam-se espécies arbóreas como castanheiras e a seringueiras, entremeadas por matas de palmeiras. Ainda pela análise da figura 1, verifica-se que essa terra indígena tem como limite natural o rio Jaci-Paraná e seu afluente, o rio Formoso, que segundo Leão et al. (2005) serve de acesso para os não indígenas, explorarem os seus recursos naturais.

A terra indígena Igarapé Ribeirão está localizada, na região noroeste da área selecionada para a análise, no município de Nova Mamoré. A terra indígena Igarapé Lage localiza-se, no extremo oeste, ocupando parte das áreas dos municípios de Nova-Mamoré e Guajará-Mirim. De acordo com o censo demográfico realizado no ano de 2010, nestas terras indígenas viviam 823 pessoas (Tabela 1). Para Leão et al. (2005), apesar das pressões antrópicas sofridas ao longo dos anos essas terras indígenas ainda resguardam em seus limites territoriais animais de caça e peixe, e espécie vegetativa como castanha, copaíba, babaçu, açaí, buriti, tapaua e a bacaba. A economia dessas terras indígenas é sustentada principalmente pelo extrativismo de Castanha do Brasil (Bertholletia excelsa) seguido da extração do óleo de copaíba (Copaifera langsdorfii) e mel, e pela venda dos produtos de roçado (LEÃO et al., 2005).

\section{Tabela 1: População Indígena por TI.}

\begin{tabular}{c|c|c|c}
\hline Terras indígenas & População & Povo & Etnia \\
\hline Igarapé Ribeirão & 210 & Wari $^{1}$ & Pacaás Novos \\
\cline { 4 - 4 } & & & Kanoé \\
\hline Igarapé Lage & 613 & \multirow{2}{*}{ Wari, } & Djeoromtxi \\
\cline { 4 - 4 } & & & Pakaa Nova \\
\hline
\end{tabular}

Fonte: IBGE, 2015. ' Vilaça (2000) que os considera um único povo, os Wari.

Já a terra indígena Uru Eu Wau Wau está localizada no extremo sul da área em estudo. Como referido esta terra é considerada a maior em área do estado de Rondônia. Diferentemente das outras terras indígenas em análise esta possui sobreposição ao Parque Nacional dos Pacaás 
Análise do desmatamento nas áreas de influência da BR-421 e as pressões sobre áreas especiais no oeste de Rondônia

Novos. Conforme os dados levantados no censo indígena do IBGE na Uru Eu Wau Wau vivem 343 indígenas distribuídos entre as etnias Amondawa, Juma Oro Win e Uru Eu Wau (IBGE, 2015). Além desses, a Fundação Nacional do Índio (FUNAI) monitora povos em isolamento voluntário nessa área.

De acordo com Rolla e Ricardo (2013) as terras indígenas Igarapé Ribeirão, Igarapé Lage, Uru Eu Wau e Karipuna estão sob a influência de atividades mineradoras, apresentando diversos processos de extração mineral, sendo que destas terras a do Uru Eu Wau apresenta um número de processos superior às outras. Segundo pesquisas de Souza et al. (2017), as maiores intensidades de processos minerários estão localizadas ao longo do Rio Madeira, que é o principal rio formador de uma das maiores bacias do estado de Rondônia.

Outra fonte de pressão e de impacto socioambiental identificado relaciona-se a produção de energia elétrica, a partir das usinas do Rio Madeira. Segundo Ribeiro et al. (2014) as usinas do Madeira situam-se a menos de $100 \mathrm{~km}$ das terras indígenas Karitiana e Karipuna e mais adiante estão as terras indígenas Igarapé Lage, Ribeirão e Uru Eu Wau Wau.

Por fim, temos as duas Unidades de Conservações presentes na área de estudo: Parque Estadual de Gujará-Mirim e Parque Nacional dos Pacaás Novos. O parque Estadual (PE) de Guajará-Mirim está localizado na região centro-oeste da área recortada para esta análise, nos municípios de Nova-Mamoré e Guajará-Mirim. Este parque foi criado a partir do Decreto ${ }^{\circ}$ 4.575 de 23 de março de 1990, apresentando uma área inicial de 258.813 ha, que com o passar dos anos, devido à especulação imobiliária, foi reduzida a uma área de 216.568 ha (SEDAM, 2015).

De acordo com o programa de Áreas Protegidas da Amazônia (ARPA), apresentado no ano de 2009, o PE de Guajará-Mirim apresenta alta diversidade de espécies vegetais e animais ocorrentes nos ecossistemas de Savana Arbórea Densa, Floresta Tropical Aberta e Densa, que são pressionados por atividades madeireiras e especulação de terras. O Parque Nacional de Pacaás Novos está localizado no extremo sul da área recortada para análise, ocupa área dos municípios de Guajará-Mirim, Nova Mamoré, Campo Novo de Rondônia, Governador Jorge Teixeira, Mirante da Serra, Alvorada d’Oeste e São Miguel do Guaporé. Este parque foi criado a partir do Decreto $n^{\circ} 84.019$ de 21 de setembro de 1979 e ocupa área de 764.801 há.

Ainda conforme os dados do ARPA este parque é caracterizado pelo Bioma Amazônia com predomínio da Floresta Ombrófila Aberta, Floresta Ombrófila Densa, contato Savana/floresta e Savana Arborizada. Em decorrência dessa diversidade próxima e dentro do 
parque ocorrem diversas atividades de conflitos como extração ilegal de madeira, invasão para demarcação e grilagem de terra, pesquisa para extração mineral ilegal, atividades de caça e pesca.

\section{MATERIAL E MÉTODO}

\section{Procedimento Metodológico}

O trabalho é sustentado por métodos indiretos de análise da paisagem, nomeadamente as geotecnologias. Além disso, a metodologia contemplou as etapas de aquisição de dados e de informações cartográficas por meio de levantamentos bibliográficos. Neste contexto, destacamse os dados em formato raster e vetorial obtidos junto ao site do Serviço Geológico dos Estados Unidos (USGS), Instituto Nacional de Pesquisas Espaciais (INPE), da Secretaria de Desenvolvimento Ambiental (SEDAM) e do Departamento Nacional de Infraestrutura de Transporte (DNIT).

Como fase subsequente realizou o Processamento Digital de Imagens (PDI), seguindo a técnica de Gonzalez e Woods (2000) que é desenvolvida em cinco etapas básicas: (i) aquisição de dados; (ii) pré-processamento; (iii) processamento; (iv) extração de informações e; (v) interpretação de padrões. Realizou-se ainda a elaboração de mapas temáticos e a análise do Índice de Pressão Antrópica.

Para tanto, utilizou-se como dados de entrada as imagens do satélite Land Remote Sensing Satellite (LANDSAT) nas versões 5, sensor Thematic Mapper (TM) e 8, sensor Operational Land Imager (OLI), para cada um dos anos em análise como mostrado na tabela 2.

Tabela 2: Dados orbitais utilizados na pesquisa.

\begin{tabular}{c|c|c|c|r}
\hline Ano em Análise & Satélite & Orbita/Ponto & Imageamento & Composição \\
\hline \multirow{3}{*}{1984} & Landsat 5 & $231 / 67$ & $04 / 08 / 1984$ & $3(\mathrm{~B})$ \\
& Landsat 5 & $232 / 67232 / 68$ & $11 / 08 / 1984$ & $4(\mathrm{G})$ \\
\cline { 2 - 4 } & Landsat 5 & $233 / 67233 / 68$ & $02 / 08 / 1984$ & $5(\mathrm{R})$ \\
\hline \multirow{3}{*}{2000} & Landsat 5 & $231 / 67$ & $16 / 08 / 2000$ & $3(\mathrm{~B})$ \\
& Landsat 5 & $232 / 67232 / 68$ & $23 / 08 / 2000$ & $4(\mathrm{G})$ \\
\cline { 2 - 4 } & Landsat 5 & $233 / 67233 / 68$ & $14 / 08 / 2000$ & $5(\mathrm{R})$ \\
\hline & Landsat 8 & $231 / 67$ & $23 / 06 / 2015$ & $4(\mathrm{~B})$ \\
& Landsat 8 & $232 / 67232 / 68$ & $30 / 06 / 2015$ & $5(\mathrm{G})$ \\
\cline { 2 - 4 } 2015 & Landsat 8 & $233 / 67233 / 68$ & $21 / 06 / 2015$ & $6(\mathrm{R})$ \\
\hline & & & &
\end{tabular}

Fonte: elaborado pelos autores 
Análise do desmatamento nas áreas de influência da BR-421 e as pressões sobre áreas especiais no oeste de Rondônia

Desses arquivos foram selecionadas e trabalhadas as bandas 3, 4 e 5, para o LANDSAT 5 e as bandas 4, 5 e 6, para o LANDSAT 8. Essas bandas foram atribuídas à composição colorida Red (vermelho), Green (Verde) e Blue (Azul) (RGB), que fornece o sistema falsa cor. Segundo Santos (2014, p. 30) com esse sistema de falsa cor "as cores dos alvos terrestres são representadas o mais próximo que o olho humano percebe, e por isso são mais adequadas para análise em tela".

Além das imagens, obtiveram-se dados em formato vetorial, que se caracterizam por limites municipais, estradas, limites das terras indígenas, das Unidades de Conservação, dentre outros. Dessa forma, todos os dados de entrada foram manipulados nos softwares Sistema para Processamento de Informações Georeferenciada (SPRING), versão 5.2.7 e ArcMap®. Todos os arquivos do banco de dados da pesquisa foram georreferenciados na Projeção Universal Transversa de Mercator (UTM) e, Datum horizontal Sistema de Referência das Américas (SIRGAS/2000).

A etapa de pré-processamento foi caracterizada pelo processo de estruturação do banco de dados e georreferenciamento das imagens. Após esse procedimento foi delimitado o recorte espacial da área em estudo através das bases cartográficas dos municípios e malha viária do estado de Rondônia. Além disso, destaca-se que a área admitida como a área de estudo nesta pesquisa, também é a área de influência indireta da rodovia BR-421. Justifica-se essa adoção, devido o uso recorrente da mesma em estudo da influência de rodovias na Amazônia, dos quais se destacam Nepstad et al. (2002); Fearnside e Laurance (2002).

Nesta etapa, além da definição do recorte espacial da área em análise, foi realizado a delimitação das áreas sob a influência da BR-421. Deste modo, as áreas de influência foram delimitadas seguindo o Estudo de Impacto Ambiental (EIA) da Implantação e Pavimentação da BR-317 do Amazonas realizado pelo DNIT no ano de 2008.

De acordo com o EIA da BR-317 do Amazonas, os impactos provenientes de empreendimentos de traçados rodoviários é de escala local e abrange, em uma área que está diretamente vinculada ao traçado da rodovia. Portanto, o EIA da BR-317 AM classifica as áreas de influência em três categorias: Área Diretamente Afetada, Área de Influência Direta e Área de Influência Indireta, descritas a seguir:

a) A Área Diretamente Afetada (ADA) refere-se à faixa de domínio com extensão de 60 metros (m), equivalente a $30 \mathrm{~m}$ para cada lado, dividido da seguinte forma: i) $10 \mathrm{~m}$ das vias de rolamento, ou seja, $5 \mathrm{~m}$ de acostamento para cada da faixa de rolamento; ii) mais 25 metros 
para cada lado, a partir do eixo da rodovia, propriamente dito como pista de rolamento. Ainda de acordo com o EIA da BR-317 AM a ADA deverá englobar além da pista de rolamento e acostamento as áreas destinadas à instalação dos canteiros de obras, bota-fora, jazidas, acampamentos e obras de drenagem.

b) A Área de Influência Direta (AID) é caracterizada por uma faixa de 10 quilômetros $(\mathrm{km})$, sendo $5 \mathrm{~km}$ para cada lado a partir do eixo da rodovia. Conforme citado no EIA da BR317 AM é nessa área que ocorre a modificação física da paisagem, o que muitas das vezes é percebido através da retirada da vegetação. Como consequência, ocorre alterações de habitats e movimentação de terra proveniente das atividades de terraplanagem.

c) A Área de Influência Indireta (AII) refere-se à faixa de domínio com extensão de 100 quilometro $(\mathrm{km})$, sendo $50 \mathrm{~km}$ de largura para cada lado a partir do eixo da rodovia. De acordo com o EIA da BR-317 AM essa área é relativamente maior em relação às outras duas já citadas neste texto, pois a AII é uma área que tem por objetivo cobrir todos os impactos com suficiente nível de relevância e intensidade decorrentes da implantação da rodovia.

Após a etapa de registro das imagens foi realizado o mosaico, com objetivo de unir todas as imagens que compõem a área em estudo ao longo do trecho da BR-421. Em seguida foi executado o recorte espacial das imagens mosaicadas a partir da área de estudo definida. Para a classificação foi aplicado o procedimento de segmentação das imagens com o objetivo de obter informação detalhada, através do método de crescimento de regiões. Assim, foi possível agrupar os pixels adjacentes e semelhantes, formando imagens homogêneas (CÂMARA et al., 1996). Este procedimento pode ser entendido como o primeiro passo para a classificação e rotulação das imagens em regiões identificadas. Essas regiões são correspondentes às feições da superfície terrestre e irão servir de base para a análise e cartografia temática (DLUGOSZ et al., 2009).

Nesta pesquisa foi utilizado o método de classificação supervisionada de Bhattacharya, onde o analista determina a partir da cor e textura a composição de informação presente na imagem. Segundo Santos et al. (2010) o classificador de Bhattacharya é um algoritmo de classificação supervisionada, que requer a seleção de áreas de treinamento, podendo utilizar as regiões separadas durante o processo de segmentação ou polígonos representativos das regiões a serem classificadas. Assim sendo, durante a fase de treinamento, certos algoritmos necessitam de alguns parâmetros que devem ser fornecidos ao sistema (MOREIRA, 2001). 
Desta forma, a determinação do limiar de similaridade foi realizada a partir de testes de hipótese, sendo este procedimento, repetido para todos os anos em análise. Contudo, o limiar variou em função das características das imagens, em que ficou definido para a imagem do ano de 1984 o limiar de 10 de similaridade e 15 para área do pixel; para a imagem do ano de 2000, o limiar adequado foi 15 de similaridade e 20 para área de pixel e para imagem do ano de 2014 o limiar adequado foi de 1500 e área de pixel 30.

Durante a etapa de treinamento para o uso do método de Bhattacharya, foram criadas diferentes classes temáticas tais como: urbano, agropecuário, queimado, rocha exposta, água, vegetação densa, vegetação secundaria, savana, ilha fluvial, zona úmida e mineração. Essas classes foram definidas a partir da experiência de campo e da análise visual de imagens. Contudo, algumas imagens possuíam nuvens e para estas foram criadas as classes nuvens e sombras a fim de evitar confusão entre os alvos.

Após o processo de treinamento elaborou-se a classificação propriamente dita e em seguida a imagem classificada foi convertida para vetor. Os vetores foram utilizados para confecções dos mapas temáticos para as três décadas em análise, possibilitando, assim a visualização da dinâmica do uso e ocupação da terra em formato vetorial no decorrer dos anos, bem como a quantificação da área das classes de uso.

\section{Índice de pressão antrópica}

O Índice de Pressão Antrópica (IPA) foi proposto por Sawyer em 1997 (RIBEIRO et al., 2014). De acordo com Santos (2014), este índice derivou do Índice de Transformação Antrópica (ITA), desenvolvido por Lémechev (1982) apud Santos (2014), que geralmente é aplicado em casos em que ocorreu a inserção de atividades impactantes ao meio.

Conforme, o Ministério do Meio Ambiente MMA (2002), esta metodologia tem por finalidade analisar e quantificar a pressão antrópica que atividades humanas exercem sobre os recursos naturais, de uma determinada região. Portanto, a mesma trata-se de um "indicador sintético de pressões econômicas e demográficas", tendo como base metodológica "as dimensões de estoque (tamanho ou densidade) e o fluxo (velocidade ou crescimento) sobre o meio ambiente" (MMA, 2002 p.69). Apresentando maior pressão onde o estoque e o fluxo são elevados e menor pressão, onde são reduzidos (SAWYER, 1997). 
Nesse contexto, Santos (2014, p. 32) destaca que esse índice é obtido a partir da "média das somas das variáveis multiplicadas pelos seus respectivos pesos" (Equação 1), variáveis essas que são interpretadas como aquelas que causam algum tipo de perturbação ao ambiente natural. Sendo as variáveis consideradas para este trabalho: o uso e cobertura da terra, focos de queimada e as estradas conforme descritas na Equação 1.

$$
\mathrm{IPA}=\frac{\Sigma(\text { uso* } \text { peso }+ \text { estradas*peso }+ \text { focos queimada*peso) }}{3}
$$

Em que: uso = a área das classes de uso da terra; estradas $=\mathrm{a}$ área ocupada por rodovias e estradas secundárias $\mathrm{e}$; focos de queimadas $=\mathrm{a}$ área com potencial de queimada, pelo fator de peso $=$ ao grau de alteração antrópica exercido por cada classe. Para Santos (2014) a determinação dos pesos é uma etapa extremamente importante no cálculo do IPA, pois é nesse momento que ocorrera o apontamento das áreas sobre maior pressão. Assim, empregou-se neste trabalho, os pesos conforme adotados por Santos (2014).

\section{RESULTADOS E DISCUSSÕES}

A análise exploratória, através da figura 2, revela como o desmatamento ocorreu na área em estudo e como isso está atrelado a construção de estradas, que apresentam padrão modal "espinha de peixe", entre os anos de 1984 a 2015. Com efeito, é possível observar que o desmatamento da área de influência da rodovia BR-421 ocorreu a partir das bordas da área recortada. Isto se verifica, principalmente na porção leste da área, onde se localiza a BR-364, e o município de Ariquemes, especialmente a sua sede. O segundo extremo do desmatamento, se localiza na porção oeste da área, onde se situam os municípios de Nova Mamoré e GuajaráMirim, às margens do rio Mamoré. Assim, a partir desses dois pontos de referências, o avanço do uso se prolongou para o interior da área em estudo, que ficou alguns anos impedido de ser ocupado pela presença do Parque Estadual de Guajará-Mirim (Figura 2).

Tal processo de ocupação explica-se devido ao fato de que, em 1984, com o fim da obra de pavimentação da rodovia BR-364, o acesso dos colonos ao interior do estado de Rondônia foi facilitado. A distribuição de terra nessa área motivava a imigração de diversos colonos que vinham para Rondônia em busca de novas terras. Para facilitar o acesso às essas terras o "Estado construiu estradas alimentadoras, que cruzam perpendicularmente a estrada principais a cada 5 $\mathrm{km}$, formando uma arquitetura de "espinha de peixe" (PFAFF et al, 2010, p.10). Contudo, a 
Análise do desmatamento nas áreas de influência da BR-421 e as

migração passou a abrir loteamentos cada vez mais distantes, o que fez com que as estradas alimentadoras fossem aumentadas, não oficialmente, mas sim, pelos próprios colonos como no caso da BR-421 (PFAFF et al, 2010).

Figura 2: Mapa de cobertura vegetal e uso da terra ao longo da BR-421 nos anos 1984, 2000 e 2015.

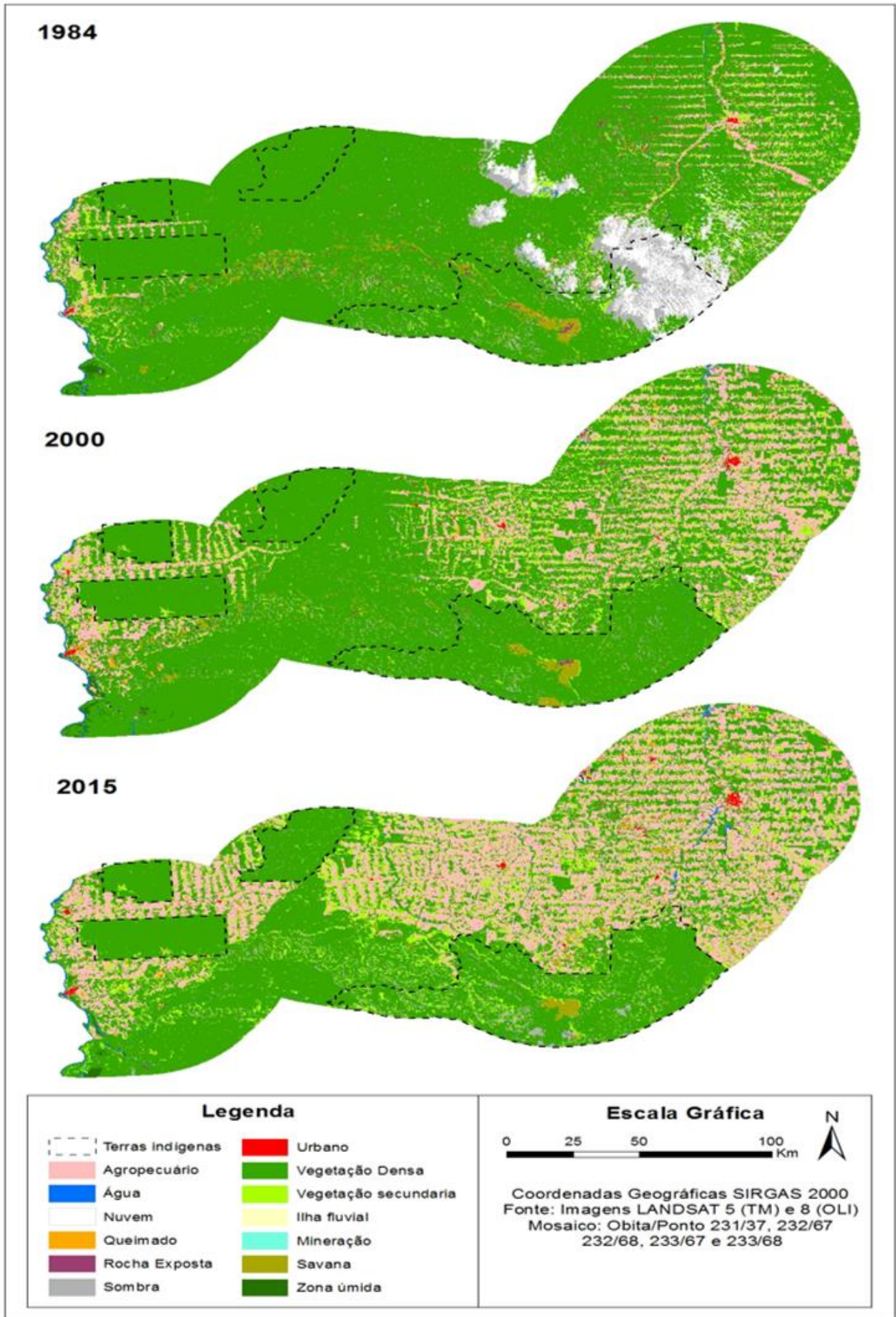

Fonte: elaborado pelos autores

Sociedade e Território - Natal. Vol. 31, N. 2, p. 282-304 
Consequentemente, para o ano de 2000, verificou-se um aumento na retirada da vegetação a partir do avanço das atividades agropecuárias, que se caracterizam na imagem pelos polígonos de coloração rosa. $\mathrm{O}$ uso e ocupação desta região se intensificaram de tal modo, que é possível observar que muitas destas áreas de agropecuária já faziam fronteira com terras indígenas e UCs, no ano de 2000. A partir deste ano é possível observar também a consolidação das manchas urbanas das cidades de Ariquemes (extremo leste), de Nova Mamoré e GuajaráMirim (extremo oeste).

Do recorte da Área Diretamente Afetada (ADA) e da Área de Influência Direta (AID), para o ano de 1984 foi possível identificar que já havia formação da estrada que caracteriza hoje a BR-421. Observou-se ainda que a retirada da vegetação da área onde se encontra a rodovia ocorria a partir da porção leste, nas proximidades da cidade de Ariquemes, área mais povoada. Entretanto, percebe-se também que para o ano de 1984 a BR-421 não era a principal responsável pela variação no uso e ocupação da terra, pois através da análise das ADA, AID e da Área de Influência Indireta (AII), identificou-se que as mudanças do uso da terra são mais sentidas na AII.

Para o ano de 2000, a partir da análise da ADA, verificou-se a consolidação do eixo da BR-421, em decorrência da presença da classe agropecuária que compõem a ADA. Para a AID observa-se a expansão das coberturas mistas e fragmentadas sob a classe vegetação densa. Porém, este aumento já era previsto, uma vez que de acordo com o EIA da BR-314 é na Área de Influência Direta, que ocorre às grandes modificações físicas da paisagem, em sua maioria, representadas pela retirada da vegetação.

No ano de 2015, foi possível perceber a consolidação da mudança do uso da terra a partir da retirada da camada vegetal em todas as áreas em análise. Na ADA e AID verificou-se que essas mudanças foram intensas em relação aos outros anos, uma vez que as duas áreas são compostas, quase totalmente, pelos polígonos representantes da classe agropecuária. Portanto, pode-se inferir que a BR-421 foi uma propulsora das mudanças ocorridas nessas áreas. Neste último período de análise observou-se ainda a consolidação da ocupação antrópica com a formações de "ilhas", ou seja, do isolamento em que as terras indígenas se tornaram nessa paisagem, além da consolidação da área urbana do município de Ariquemes (à leste do recorte em análise).

Além do exposto, verificou-se que para todos os anos em análise as grandes mudanças de conversão do uso e cobertura da terra ocorreram na AII, corroborando com os resultados de 
Análise do desmatamento nas áreas de influência da BR-421 e as

Alves et al. (1999). Segundo os referidos autores, cerca de $75 \%$ das áreas com retirada da cobertura vegetal, ocorreram na faixa de $50 \mathrm{~km}$, que nesse estudo representa a AII.

Do processamento das imagens foi possível constatar que a vegetação de floresta foi suprimida, já que no ano de 1984 ocupava cerca de 78,71\% da área de estudo, sendo reduzida, em 2015 para 53,54\%, ou seja, com taxa de variação negativa de 33,25\%. Já a classe de vegetação secundária apresentou aumento nos três anos em análise. Em 1984 essa classe ocupava $3,42 \%$ da área e em 2015, cresceu para 11,22\%. Fato que revela, que foi neste período, que as atividades antrópicas começaram a se intensificar, sobre as áreas de florestas naturais. Além disso, as classes representadas pelos usos: agropecuário, urbano, queimada e mineração em 1984, que ocupavam somente 4,95\% da área de estudo, passaram a ocupar juntamente, cerca de 30,54\% da área em 2015 (Tabela 3).

Tabela 3: Quantificação das classes de uso e cobertura da terra.

\begin{tabular}{lcccc}
\hline Ano & 1984 & 2000 & 2015 & $\begin{array}{c}\text { Variação } \\
(1984 \text { a 2015) }\end{array}$ \\
\hline Classe de Uso & & Área em \% & 5,36 \\
\hline Savana & 2,24 & 1,42 & 2,36 & $\mathbf{5 2 , 5 4}$ \\
Vegetação Densa & $\mathbf{7 8 , 7 1}$ & $\mathbf{6 9 , 2 2}, \mathbf{3 3}$ \\
Vegetação Secundária & $\mathbf{3 , 4 2}$ & $\mathbf{7 , 6 0}$ & $\mathbf{1 1 , 2 2}$ & $\mathbf{2 2 7 , 0 7}$ \\
Agropecuário & $\mathbf{4 , 5 8}$ & $\mathbf{1 7 , 1 9}$ & $\mathbf{2 9 , 6 7}$ & $\mathbf{5 4 7 , 8 2}$ \\
Urbano & 0,12 & 0,34 & 0,36 & 200,00 \\
Queimado & $\mathbf{0 , 2 4}$ & $\mathbf{0 , 8 0}$ & $\mathbf{0 , 4 6}$ & $\mathbf{9 1 , 6 7}$ \\
Mineração & 0,01 & 0,02 & 0,05 & 400,00 \\
Rocha & 0,83 & 0,35 & 0,12 & $-85,54$ \\
Ilha Fluvial & 0,09 & 0,04 & 0,00 & $-100,00$ \\
Zona Úmida & 0,38 & 0,93 & 0,45 & 18,42 \\
Água & 0,40 & 0,46 & 0,68 & 70,00 \\
Nuvem & 4,76 & 0,06 & 0,00 & $-100,00$ \\
Sombra & 4,30 & 1,68 & 2,19 & $-49,07$ \\
\hline
\end{tabular}

Fonte: elaborado pelos autores

Nesse sentido, o aumento de atividades agropecuárias pode ser justificado, em parte, pela ampliação no número de cabeças bovinas, conforme os dados do Instituto Brasileiro de Geografia e Estatística (IBGE, 2015). Desta forma, a classe agropecuária cresceu a uma taxa de variação entre 1984 a 2015, da ordem de 547,82\%, sendo a maior taxa entre as classes de uso da terra analisadas.

A partir da análise das tabelas 4 e 5 observou-se que a conversão das florestas é mais expressiva na ADA. Um indício disso é a presença do baixo índice de porcentagem na classe vegetação densa, que na ADA apresentou uma variação de $-90,82 \%$, sendo uma das mais baixas, devido a conversão para a classe agropecuária de variação igual a 140,14\%. 
Tabela 4 - Quantificação das classes de uso e cobertura da terra na ADA da BR-421.

\begin{tabular}{|c|c|c|c|c|}
\hline \multicolumn{5}{|c|}{ ADA (\%) } \\
\hline Ano & 1984 & 2000 & 2015 & $\begin{array}{c}\text { Variação } \\
(1984 / 2015)\end{array}$ \\
\hline Classe de Uso & \multicolumn{4}{|c|}{ Área $(\%)$} \\
\hline Savana & 2,28 & 0,11 & 1,39 & $-39,04$ \\
\hline Vegetação Densa & 35,28 & 13,03 & 3,24 & $-90,82$ \\
\hline Vegetação Secundária & 7,06 & 8,02 & 6,41 & $-9,21$ \\
\hline Agropecuário & 34,28 & 68,06 & 82,32 & 140,14 \\
\hline Urbano & 2,22 & 7,53 & 4,81 & 116,67 \\
\hline Queimado & 2,75 & 1,56 & 0,74 & $-73,09$ \\
\hline Mineração & $\mathbf{0 , 0 0}$ & $\mathbf{0 , 0 2}$ & 0,06 & 200,00 \\
\hline Rocha & 0,51 & 0,21 & 0,00 & $-100,00$ \\
\hline Ilha Fluvial & 0,73 & 0,23 & 0,00 & $-100,00$ \\
\hline Zona Úmida & 0,21 & 0,60 & 0,52 & 147,62 \\
\hline Água & 0,18 & 0,16 & 0,49 & 172,22 \\
\hline Nuvem & 9,28 & 0,03 & 0,00 & $-100,00$ \\
\hline Sombra & 5,25 & 0,46 & 0,06 & $-98,86$ \\
\hline
\end{tabular}

Fonte: elaborado pelos autores

Mesmo assim, de todas as classes verificou que a mineração é a que têm a maior influencia na ADA, pois apresentou um aumento gradativo em todos os anos, com uma variação de $200 \%$ em relação à área total. Por sua vez, destaca-se ainda que a classe agropecuária apresentou um aumento em todos os anos. Em 2015, ocupava 82,32\% da ADA, ou seja, neste ano a ADA é praticamente caracterizada por propriedades rurais.

Outro fator que merece destaque nessa análise foi a classe urbana que apresentou valor alto somente no ano de 2000. Este alto valor é resultado de confusão espectral com alvos representativos da classe de mineração. Essa confusão era esperada dado que nos garimpos o material inerte (areia e solo exposto), também é identificado nas cidades.

Na AID (Tabela 5) verificou-se que a classe de vegetação densa, para o ano de 1984, representava $75,07 \%$ da área, e para o ano de 2015 a mesma representava $29,86 \%$. O que demonstra que mesmo a rodovia tendo se mantido intransitável até o ano de 2014, não foi um obstáculo para a ocupação dessa região. Do mesmo modo, verificou-se que a classe vegetação secundária cresceu 211,62\% entre 1984 a 2015, à medida que a classe agropecuária aumentava, demonstrando que esse tipo de atividade antrópica apresenta grande influência em áreas naturais. Por outro lado, a classe agropecuária cresceu a uma taxa de 543,58\%.

Tabela 5: Quantificação das classes de uso e cobertura da terra na AID da BR-421. AID (\%)

\begin{tabular}{|c|cccc}
\hline \multicolumn{1}{l}{ Ano } & \multicolumn{1}{c}{1984} & 2000 & 2015 & Variação \\
\hline \multirow{2}{*}{297} & & Sociedade e Território - Natal. Vol. 31, N. 2, p. 282-304 \\
& & Jul./Dez. de 2019 / ISSN: 2177-8396
\end{tabular}


Análise do desmatamento nas áreas de influência da BR-421 e as pressões sobre áreas especiais no oeste de Rondônia

\begin{tabular}{lcccc}
\hline & \multicolumn{5}{c}{ Área (\%) } \\
\hline Classe de Uso & \multicolumn{1}{c}{ (1984/2015) } \\
\hline Savana & 2,41 & 1,34 & 4,44 & 84,23 \\
Vegetação Densa & $\mathbf{7 5 , 0 7}$ & $\mathbf{6 0 , 1 4}$ & $\mathbf{2 9 , 8 6}$ & $\mathbf{- 6 0 , 2 2}$ \\
Vegetação Secundária & $\mathbf{4 , 9 9}$ & $\mathbf{1 0 , 0 0}$ & $\mathbf{1 5 , 5 5}$ & $\mathbf{2 1 1 , 6 2}$ \\
Agropecuário & $\mathbf{8 , 0 3}$ & $\mathbf{2 9 , 1 9}$ & $\mathbf{5 1 , 6 8}$ & $\mathbf{5 4 3 , 5 8}$ \\
Urbano & 0,50 & 1,33 & 1,49 & 198 \\
Queimado & 0,81 & 1,08 & 0,67 & $-17,28$ \\
Mineração & 0,03 & 0,01 & 0,05 & 66,66 \\
Rocha & 1,34 & 0,44 & 0,12 & $-91,04$ \\
Ilha Fluvial & 0,16 & 0,05 & 0,00 & -100 \\
Zona Úmida & 0,16 & 0,85 & 0,48 & 200 \\
Água & 0,27 & 0,29 & 0,96 & 255,55 \\
Nuvem & 7,13 & 0,08 & 0,00 & -100 \\
Sombra & 6,57 & 1,93 & 1,39 & $-78,84$ \\
\hline Fonte: elaborado pelos autores & & & &
\end{tabular}

Nesse sentido, destaca-se o estudo de Carvalho (2014), que revela que é devido ao fator de intervenção das classes de uso antrópicos, propiciada pelas vicinais das estradas que a vegetação adjacente se tornou mais suscetível a efeitos de borda, a invasão de espécies exóticas, incêndios e consequentemente a perda de hábitat da fauna e flora silvestre.

A partir de questionários semiestruturados inquiriu 7 estudantes indígenas que frequentam o curso de Licenciatura Básica Intercultural da Universidade Federal de Rondônia, no campus da cidade de Ji-Paraná e, que vivem na terra indígena Igarapé Lage. Todos os inquiridos perceberam a Estrada Parque como vetor de pressão sobre a terra indígena em que vivem. Nesse sentido, tentando representar as preocupações destas comunidades a FUNAI interpelou a liberação das obras na Estrada Parque, mas sua ação foi negada na $6^{\text {a }}$ Turma do Tribunal Regional Federal (TRF1).

Por fim, realizou-se o cálculo do Índice de Pressão Antrópica para as áreas de influência da rodovia federal BR-421. Os resultados revelaram que aproximadamente 58,25\% da área encontram-se pressionada, com o IPA baixo e, 41,75\%, com IPA moderado. Destaca-se ainda que foram obtidos IPA alto e muito alto, porém em representações de pequenas áreas, tornandose imperceptíveis em relação a área total (Tabela 6).

Tabela 6 - Dados quantitativos do IPA na área de estudo.

\begin{tabular}{cccc}
\hline Nível & IPA & Área $\mathbf{k m}^{\mathbf{2}}$ & $\begin{array}{c}\text { Área } \\
(\boldsymbol{\%})\end{array}$ \\
\hline Baixo & $1-2,7$ & 19378,17 & 58,25
\end{tabular}




\begin{tabular}{cccc} 
Moderado & $2,8-4,5$ & 13887,48 & 41,75 \\
Alto & $4,6-6,3$ & 0,25 & 0 \\
Muito Alto & $6,4-8,1$ & 0,21 & 0 \\
Total & $\mathbf{1 ~ a ~ 1 0}$ & 33266,11 & 100 \\
\hline
\end{tabular}

Fonte: elaborado pelos autores

Assim, observou-se que o IPA predominante nas áreas de entorno das terras indígenas, foram de baixo a moderado (Figura 3). Nesse sentido, destaca-se que nas terras indígenas Karipuna e Uru Eu Wau Wau o IPA predominante foi o baixo, ocupando 50,44\% e 55,26\% da área de entorno, das referidas terras indígenas, respectivamente. Contudo, esperava-se que o IPA para AID da terra indígenas Uru Eu Wau Wau fosse de alto a muito alto, uma vez que a rodovia BR-421 exerce grande influencia sobre a mesma. Porém o baixo valor obtido deve-se ao fato da presença do Parque Estadual de Guajará-Mirim, que junto às terras indígenas servem como barreiras para o avanço de atividades antrópicas na região.

\section{Mapa 3- Índice de Pressão Antrópica no entorno das terras indígenas na área de influência da BR-421.}

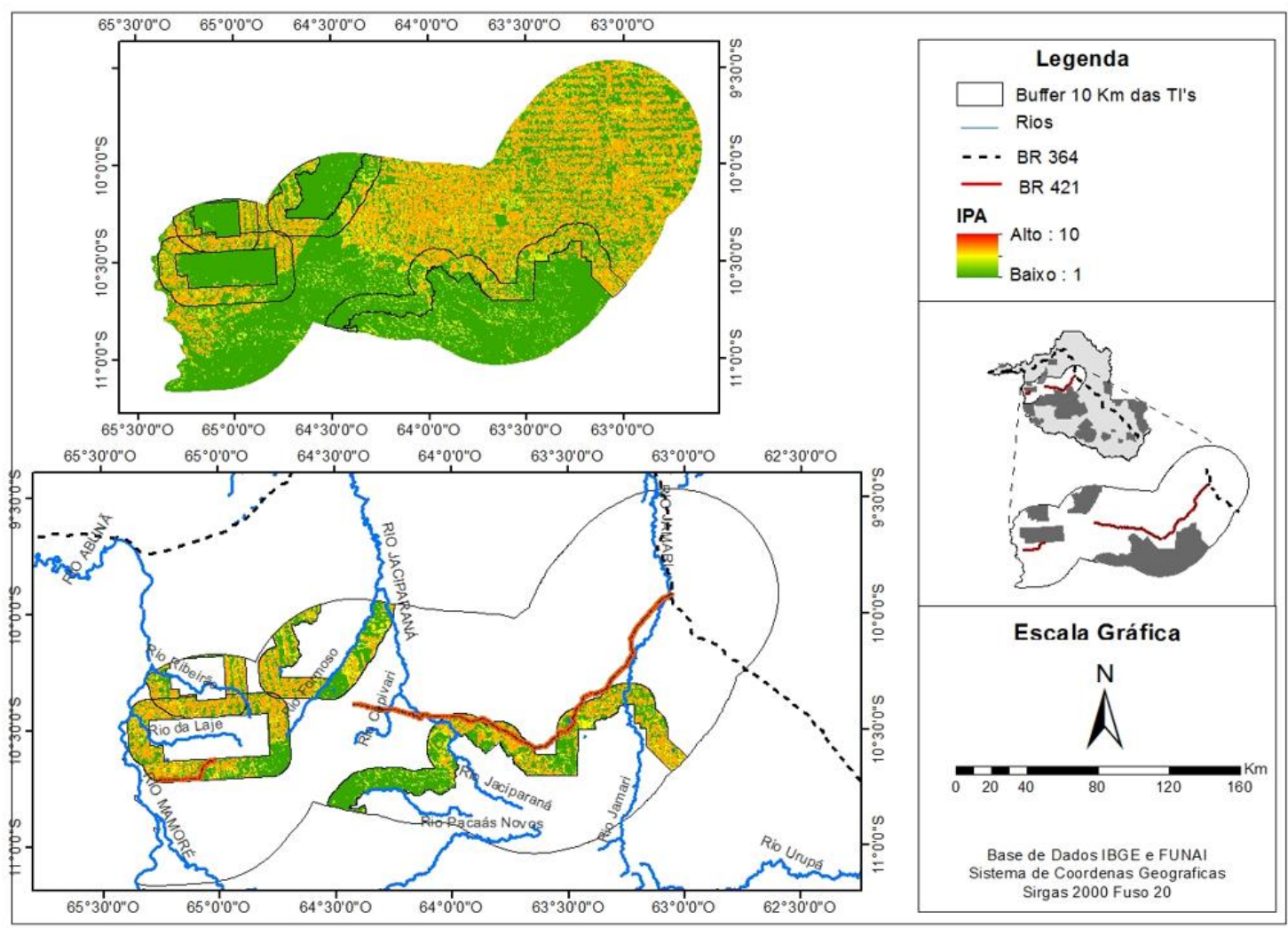

Fonte: elaborado pelos autores

Já as terras indígenas Igarapé Ribeirão e Igarapé Lage tiveram em sua área de entorno a predominância do IPA moderado, ocupando 64,73\% e 58,94\%, respectivamente. Para a terra 
Análise do desmatamento nas áreas de influência da BR-421 e as

indígena Igarapé Lage realmente esperava-se um IPA de moderado a alto, uma vez que sua área de entorno é totalmente tocada pela rodovia BR-421. Por conseguinte, em relação às outras terras indígenas analisadas, essa duas foram as que apresentaram o IPA mais alto.

Nesse contexto, acredita-se que os IPA baixo a moderado refletem a situação em que a BR-421 se encontrava até o ano de 2014, ou seja, sem muito uso. Todavia, com a sua pavimentação, este cenário poderá mudar e as áreas de proteção especial, talvez não consigam mais, por si só, conter as pressões de diversas atividades antrópicas sobre as mesmas. Assim, diante deste novo panorama, concordamos com Santos $(2014$, p.232) quando o autor propõe "que no entorno das terras indígenas, sejam criadas áreas de amortecimento e corredores ecológicos". Estes poderão ser implantados a partir das áreas de proteção permanente, nas beiras dos rios e reservas legais. Essas iniciativas contribuirão para a sobrevivência física dos povos indígenas e de suas tradições culturais.

\section{CONCLUSÕES}

Os diversos dados gerados nesta pesquisa colaboram para uma melhor reflexão a respeito da relevância das áreas especiais a conservação, como as terras indígenas. Assim, a partir dos resultados obtidos foi possível concluir que:

- A malha viária na Amazônia impulsiona o desmatamento, fato observado com a implantação da rodovia federal BR-421;

- A retirada da cobertura vegetal na área em estudo, no passado sofreu influência da rodovia federal BR-364 e, se consolidou no ano de 2000 através da implantação da rodovia federal BR-421;

- A variação da paisagem revelou conversão de uso e cobertura da terra, para a classe agropecuária da ordem de 547,82\%, dentre todos os períodos analisados;

-Das três áreas sob influência da rodovia federal BR-421, a Área de Influência Direta (AID) foi a que apresentou a maior taxa de crescimento de conversão, da floresta em áreas agropecuárias, da ordem de 543,58\%.

\section{REFERÊNCIAS}

ALVES, Diógenes S.; COSTA, Wanderley M. da; ESCADA, Maria Isabel; LOPES, Eymar; SOUZA, R.C.M. de. Análise da distribuição espacial das taxas de desflorestamento dos 
municípios da Amazônia Legal no período 1991-1994. INPEAMZ- R04/98, Instituto Nacional de Pesquisas Espaciais, Brasil. 1999.

AMARAL, José Januário. "Rondônia: colonização de novas terras". Revista de Educação, Cultura e Meio Ambiente, Belém, v. 1, n. 1, p. 1-5, 1998. Disponível em:

http://www.revistapresenca.unir.br/artigos_presenca/11josejanuario_rondoniacolonizacaoden ovasterras.pdf. Acesso em: 15 mai. 2017.

ARCADIS TETRAPLAN. Programa de Proteção das Terras indígenas Karitiana e Karipuna na área de influência da UHE Santo Antônio. 2011.

BASTOS, Alexis de Sousa. A Dinâmica da Ocupação e Seus Reflexos para Estabilidade do Meio Físico na Terra Indígena Uru Eu Wau Wau/RO e seu Entorno. 2009. Dissertação (Mestrado em Geografia) - Programa de Pós-Graduação em Geografia, UNIR, Porto Velho - RO.

BORGES, Luciana Riça Mourão. Políticas Territoriais na Fronteira: o programa de aceleração do Crescimento e as transformações em Rondônia no início do séc. XXI. 2012. Dissertação (Mestrado em Geografia) - Programa de Pós-Graduação em Geografia Humana da Faculdade de Filosofia, Letras e Ciências Humanas, CAPH/FFLCH/USP, São Paulo - SP.

CÂMARA, Gilberto; SOUZA, Ricardo Cartaxo Modesto de; FREITAS, Ubirajara Moura de, GARRIDO, Juan. "Spring: integrating remote sensing and GIS by object-oriented data modelling" Computers \& Graphics, v. 20, n. 3, p. 395-403, 1996.

CARVALHO, Daniela Paiva. "Caracterização das voçorocas na BR - 174: Trecho Manaus Presidente Figueiredo (Amazonas)”. Revista Geográfica Acadêmica, Boa Vista, v. 08, p. 515, 2014.

CASTILHO, Denis. Modernização territorial e redes técnicas em Goiás. 2014. Tese (Doutorado em Geografia) - Programa de Pós-Graduação em Geografia, IESA/UFG, Goiás GO.

CIM, Salvador. O processo migratório de ocupação no estado de Rondônia: visão histórica. Porto Velho: Ed. UFRO, 2003.

DLUGOSZ, Fernando Luís; ROSOT, Nelson Carlos; ROSOT, Maria Augusta Doetzer; OLIVEIRA, Yeda Maria Malheiros de. "Índice para a avaliação de segmentação de imagens". Revista Floresta, v. 39, n. 1, p. 131-143, 2009.

DNIT, Departamento Nacional de Infraestrutura de Transportes. Estudo de Impacto Ambiental da BR-317 AM. Rio de Janeiro, RJ, v. 1, c. v, p. 4-9, 2008.

EULER, Ana et al. O fim da floresta? A devastação das Unidades de Conservação e Terras Indígenas no Estado de Rondônia. Grupo de Trabalho Amazônico - GTA. Rondônia. 2008. Disponível em: https://fase.org.br/wp-content/uploads/2010/01/O_fim _da_floresta.pdf. Acesso em 20 abr. 2018. 
FEARNSIDE, Philip M.; FERREIRA, Gabriel Lima de. "Roads in Rondônia: highway construction and the farce of unprotected reserves in Brazil's Amazonian Forest".

Environmental Conservation, v. 11, n. 4, p. 358-360, 1984.

FEARNSIDE, Philip M. A ocupação humana de Rondônia: impactos, limites e planejamento. Brasília: Assessoria Editorial e Divulgação Científica, 1989. Relatório de pesquisa.

FEARNSIDE, Philip M.; LAURANCE, Willian F. "O future da Amazônia: os impactos do programa Avança Brasil”. Ciência Hoje, v. 31, n. 1, p. 61-64, mai.2002.

FEARNSIDE, Philip M. "Desmatamento na Amazônia brasileira: história, índices e consequências". Megadiversidade, v. 1, n. 1, p. 113-123, 2005.

FUNDAÇÃO NACIONAL DO ÍNDIO (FUNAI). Terras Indígenas Homologas em Rondônia. Disponível em: <http://www.funai.gov.br/index.php/indios-no-brasil/terrasindigenas $>$. Acesso em 21 de setembro de 2014.

GONZALEZ, Rafael C.; WOODS, Richard E. Processamento de imagens digitais. Publisher: Edgard Blucher, 2000.

GREENBAUM, Linda, "The Failure to Protect Tribal Peoples: the POLONOROESTE case in Brazil". Cultural Survival Quarterly, v. 8, n. 4, p.76-77, 1984.

IBGE - Instituto Brasileiro de Geografia e Estatística. Cidades. 2015. Disponível em: http://www.ibge.gov.br/cidadesat/topwindow.htm?1. Acesso em: 02 fev. 2015.

INPE, Imagens do satélite LANDSAT 5. In: Instituto Nacional de Pesquisas Espaciais. 2012. Disponível em: http://www.dgi.inpe.br. Acesso em 21 setembro. 2014.

KOHLHEPP, Gerd. "Conflitos de interesse no ordenamento territorial da Amazônia brasileira”. Estudos Avançados, v.16, n.45, p.37-61, 2002.

LAND REMOTE SENSING SATELLITE (LANDSAT). Disponível em: http://glovis.usgs.gov/.com. Acesso: em 13 de setembro de 2015.

LEÃO, Auxiliadora C. S; AZANHA, Gilberto; MARETTO, Luiz. C. "Diagnóstico final e avaliação de impactos nas terras indígenas Karitiana, Karipuna, Lage, Ribeirão e Uru-EuWauWau". In: Estudo socioeconômico sobre as terras e povos indígenas situados na área de influência dos empreendimentos do rio Madeira (UHES Jirau e Santo Antonio). Brasília: CTI, 2005.

MARCUARTÚ, Bianca Chaves; COELHO, Andréa Santos dos; MANESCHY, Rosana Quaresma; CANTO, Otávio do. "Uso e cobertura da terra na Floresta Nacional do Jamanxim, novo progresso, Pará: considerações sobre sua desafetação. Estudos Geográficos, v. 15, n. 2, p. 35-56, 2017. 
MMA- Ministério do Meio Ambiente. Sistema Nacional de Unidades de Conservação da Natureza - SNUC. Lei n 9.985, 18 de julho de 2000. Decreto ${ }^{\circ} 4.340$, de 22 de agosto de2002. 2. Ed. Aum. Brasília: MMA/SBF, 2002. 52p.

MOREIRA, Maurício Alves. Fundamentos do sensoriamento remoto e metodologias de aplicação. Viçosa -MG: Ed. UFV, 2001.

NEPSTAD, Daniel Curtis; MCGRATH, David; ALENCAR, Ane; BARROS, Ana Cristina; CARVALHO, Georgia; SANTILLI, Márcio; VERA-DIAZ, Maria. "Frontier governance in Amazonia". Science, v. 295, n. 629, p. 629-631, jan. 2002.

OLIVEIRA, Ovídio Amélio de. História, desenvolvimento e Colonização do Estado de Rondônia. Porto Velho: Dinâmica Editora e Distribuidora, 2003.

PEDLOWSKI, Marcos, DALE, Virginia; MATRICARDI, Eraldo. "A criação de áreas protegidas e os limites da Conservação ambiental em Rondônia". Ambiente e Sociedade, Ano II, n. 5, p. 93-107, 1999.

PFAFF, Alexander; BARBIERI, Alisson; LUDEWIGS, Thomas; MERRY, Frank; PERZ, Stephen; REIS, Eustáquio. "Impactos de Estradas na Amazônia Brasileira". Amazonia and Global Change Geophysical Monograph Series, v. 186. Tradução: Ivani Pereira 2010.

PONS, Joana Maria Seguí; REYNÉS, Maria Rosa Martínez. Geografia de los transportes. Palma de Mallorca: Universitat de les illes Balears, 2004.

RIBEIRO, Maria Ivanilse Calderon; SANTOS, Alex Mota dos; LOPES, Jéssica Maiara Alves.; CEREDA, Maria Lúcia. "Aplicação de geotecnologias nas pesquisas em geografia socioambiental no município de Porto Velho - Rondônia". Revista de Administração e Negócios da Amazônia, v.6, n.3, p. 21-37, 2014.

RIOTERRA. Contexto prévio: Rondônia. 2011. Disponível em:

http://www.rioterra.org.br/wpcontent/uploads/2011/07/analise_socioeconomica_do_entorno_ da_area_de_concessao_publica_parte_ii.pdf. Acesso em: 27 set. 2018.

RODRIGUE, Jean-Paul; COMTOIS, Claude; SLACK, Brian. The geography of transport systems. Abingdon, Oxon, England; New York: Routledge, 2006. Disponível em:

https://transportgeography.org/wp-content/uploads/GTS_Third_Edition.pdf. Acesso em: nar. 2018.

ROLLA, Alicia; RICARDO, Fany. Mineração em Terras Indígenas na Amazônia brasileira 2013. São Paulo: Instituto Socioambiental, 2013. Disponível em:

https://www.socioambiental.org/sites/blog.socioambiental.org/files/publicacoes/mineracao201 3_v6.pdf. Acesso em: jun. 2017.

SANTOS, Alexandre Rosa dos; PELUZIO, Telma Machado Oliveira de.; SAITO, Nathália Suemi. Spring 5.1. 2 - Passo a passo: aplicações práticas. Alegre: Caufes, 2010.

SANTOS, Alex Mota dos. Cartografia dos povos e das terras indígenas em Rondônia. 
2014. Tese (Doutorado em Geografia) - Programa de Pós-Graduação em Geografia, UFPR. Curitiba - PR.

SANTOS, Alex Mota dos; PEREIRA, W. A.; LOCATELLI, M. “Transformações no espaço rondoniense e os impactos ambientais sobre os parques estaduais". In: XIMENS, Claudia. Cleomar.; LOCATELLI, Marilia; SOUZA JUNIOR, Benedito Matos de. Transformação Espacial: construção do espaço geográfico. Porto Velho: Ed. CRV, 2018.

SAWYER, Donald. Índice de pressão antrópica: uma proposta metodológica. Brasília, 1997.

SEDAM, Secretaria de Estado de Desenvolvimento Ambiental. Unidades de Conservação. Disponível em: http://www.sedam.ro.gov.br/index.php/component/content/article/110unidade-de-conservacao. Acesso em 03 de março de 2017.

SOUZA, Vinícius A. Sikora de; RUDKE, Anderson Paulo; SANTOS, A. M. D.; ROTUNNO FILHO, Otto Corrêa. "O uso de programas de geoprocessamento na determinação de impactos gerados pela mineração na Amazônia”. Revista Internacional de Tecnología, Ciencia y Sociedad, v. 6, n. 1, p. 1-15, 2017.

VILAÇA, Aparecida. "O que significa tornar-se outro? Xamanismo e contato interétnico na Amazônia”. RBCS - Revista Brasileira de Ciência Sociais, v. 15 n. 44, p. 56-12, 2000.

Recebido em Novembro de 2019

Aceito em Dezembro de 2019

Publicado em Dezembro de 2019 